Saudi Journal of Oral and Dental Research

Abbreviated Key Title: Saudi J Oral Dent Res

ISSN 2518-1300 (Print) |ISSN 2518-1297 (Online)

Scholars Middle East Publishers, Dubai, United Arab Emirates

Journal homepage: http://scholarsmepub.com/sjodr/

Case Report

\title{
Functional and Esthetic Rehabilitation of a Young Patient with Amelogenesis Imperfecta
}

\author{
Essari Amira $^{*}$, Gharbi Imene ${ }^{2}$ \\ ${ }^{1}$ Resident in Pediatric Dentistry, Dentistry Department, Hospital La Rabta, Tunis, Tunisia \\ ${ }^{2}$ Professor in Pediatric Dentistry, Head of Dentistry Department, Hospital la Rabta Tunis, Tunisia
}

DOI: $10.36348 /$ sjodr.2020.v05i01.001

| Received: 11.12.2019 | Accepted: 20.12.2019 | Published: 11.01 .2020

*Corresponding author: Essari Amira

Abstract

Amelogenesis imperfecta (AI) is a disorder group of hereditary development that affects the dental enamel structure in the primary and permanent teeth. The enamel may be hypoplastic, hypomineralised, hypomature or both and teeth affected may be discolored, sensitive or prone to disintegration. AI exists in isolation or associated with other abnormalities in syndromes. It may show autosomal dominant, autosomal recessive, sex-linked and sporadic inheritance patterns. Clinical treatment is important to address the esthetic appearance of affected teeth, reduce dentinal sensitivity, preserve tooth structure, and optimize masticatory function. The purpose of this paper was to describe the diagnosis, treatment planning, and dental rehabilitation of a girl with autosomal recessive amelogenesis imperfecta. Through this observation, we conclude that the Rehabilitation of a patient with amelogenesis imperfecta (AI) from both the functional and esthetic standpoints represents a challenge. The complexity of the condition requires an interdisciplinary approach for optimal treatment outcomes.

Keywords: Amelogenesis imperfecta, multidisciplinary approach, functional and esthetic rehabilitation, Paediatric dentistry.

Copyright @ 2020: This is an open-access article distributed under the terms of the Creative Commons Attribution license which permits unrestricted use, distribution, and reproduction in any medium for non-commercial use (NonCommercial, or CC-BY-NC) provided the original author and source are credited.

\section{INTRODUCTION}

Amelogenesis imperfecta (AI) is a group of low prevalence hereditary conditions that cause alterations in the structure and chemical composition of the enamel matrix during development $[1,2]$. Currently, the diagnosis of AI involves a clinical and radiographic examination, and when possible, morphological analysis, using ground sections and scanning electron microscopy of the teeth, and molecular genetic analysis of the DNA samples can be performed [3,2].

AI is classified into three main types that are related to the stages of the tissue formation process [4]. A fault in the secretory stage of amelogenesis produces the hypoplastic type of AI, which is characterized by enamel that is thinner than normal and that contrasts normally from dentine in the radiographic analysis [4, 5]. In hypocalcified AI, there is an alteration in the initial mineralization of the secretory stage; the enamel initially develops normal thickness, is orange-yellow at eruption and consists of poorly calcified matrix that is rapidly lost during normal function. In addition, the enamel has a lower radiopacity than the dentin [5-7].
In hypomature AI, the defect occurs in the maturation stage of the enamel; is of normal thickness but has a mottled appearance; is slightly softer than normal enamel; and chips from the crown. Radiographically, it presents with approximately the same radiodensity as that of dentin [4-8].

Other dental anomalies may be associated with AI: taurodontism, pulp stones, delayed tooth eruption, anterior open bite or craniofacial anomaly [9].

Surprisingly, no increased incidence of caries has been reported. [10] The main sequel to patients with $\mathrm{AI}$ is represented by dental sensitivity and breakdown of hard tissues due to weak mechanical properties of affected teeth. Still, there are marked impacts on children and adolescents as a result of AI, including aesthetics, function, and psychosocial aspects.

Thus, attention should be taken to multiapproach treatment, aiming to determine the correct immediate and long-term planning follow-up [11]. 
This paper aims to demonstrate, through a case report, a rehabilitation treatment by a noninvasive and multidisciplinary approach of a pediatric patient with AI.

\section{CASE REPORT}

An 8-year-old girl referred to the Pediatric Dentistry department at the RABTA University Hospital-Tunis-Tunisia. Her medical and family history revealed no etiologic explanation.

According her mother, she complained with pain while eating, extreme sensitivity during tooth brushing. The patient showed very low self-esteem because of her poor appearance. She reported bullying at school and didn't want to smile.

Intraoral examination revealed a mixed dentition with the eruption of permanent lower incisors and first molars. The enamel of all remaining teeth was hypoplastic and yellow-brown in color. The surfaces of the teeth were rough, and the enamel was either not visible or very thin over the crowns of all teeth.

The dentin, where it was exposed, was brown and hypersensitive.

Primary molars were the most affected teeth showing reduced crown height (Fig. 1)
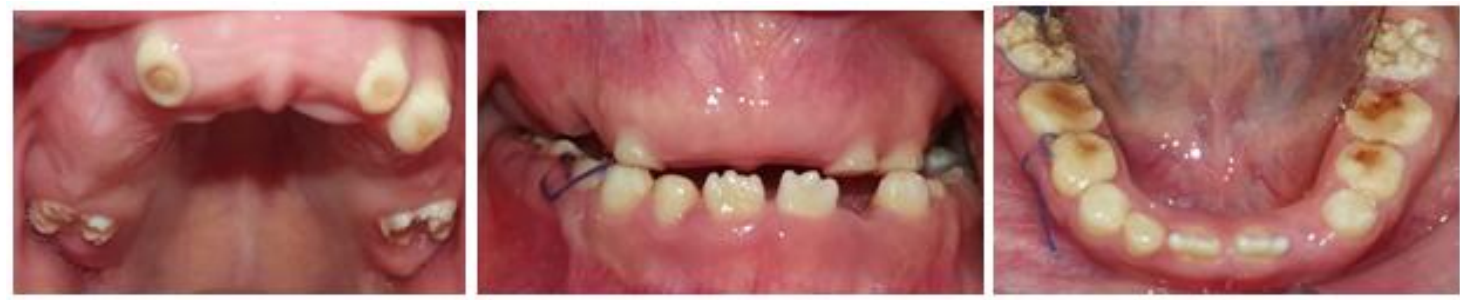

Fig-1: Initial intraoral aspect of 8-year-old patient with hypoplastic amelogenesis imperfecta

The panoramic radiograph confirmed a reduction in the enamel thickness and no clarity of amelo-cement junctions without any root abnormalities (Fig. 2).

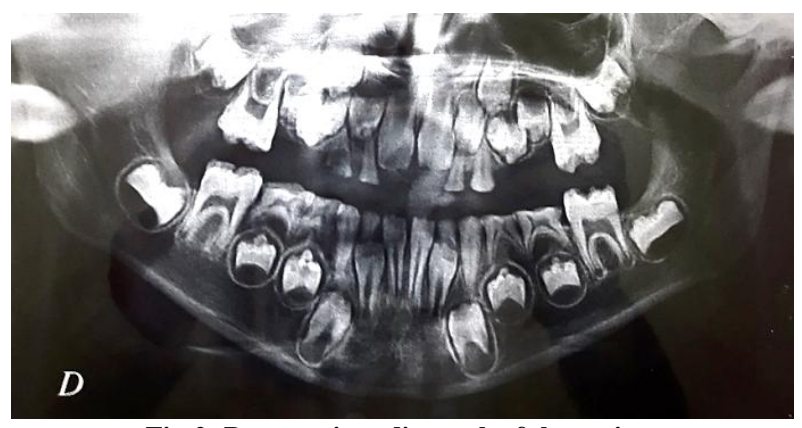

Fig-2: Panoramic radiograph of the patient

After thorough examination, the patient was diagnosed as having generalized hypoplastic amelogenesis imperfecta (AIH) affecting both the primary and permanent dentition.

\section{Multidisciplinary treatment was planned following 5} objectives:

\section{- Pain prevention and treatment}

- Protection of dental tissue integrity in order to maintain occlusal function and limit dental biofilm retention

- Preservation of vitality of permanent teeth emerged in the oral cavity

- Noninvasive rehabilitation that allowed evolution during growth

- Restoration of smile aesthetics.
The treatment of choice was oral rehabilitation with resin filled celluloid forms for upper and lower incisors and canines and stainless steel crowns on the primary molars and first permanent molars.

The incisors and canines were isolated with a rubber dam and direct dental composite restorations were placed ( Fig. 3)Teeth were not prepared; we etched with $35 \%$ Phosphatidic acid for $30 \mathrm{~s}$, rinsed for $30 \mathrm{~s}$ with air and water. Then teeth were air dried, adhesive was applied with an applicator tip, excesses were removed with air before polymerization for $45 \mathrm{~s}$. affected enamel was not removed but bonding was directly applied to it. As enamel surface appeared rough, a flow composite was applied and served as intermediate material. Its higher fluidity and wettability would allow penetrating enamel roughness. Because tooth morphology of anterior teeth was altered, "Odus" molds were useful to offer a correct and esthetic restoration. Finishing and polishing were achieved with abrasive discs [12].

On primary and first permanent molars, the choice of treatment was stainless steel crowns because the occlusal morphology was lost (Fig. 3).

The stainless steel crowns were selected and the adjustments were made with carborundum disc. The interproximal and occlusal tooth surfaces were prepared with diamond burs. Glass ionomer cement was used and placed inside the crowns. The patient's vertical dimension of occlusion was reestablished. This step was combined with a gingivectomy and crown lengthening was done before placing stainless steel crowns. 


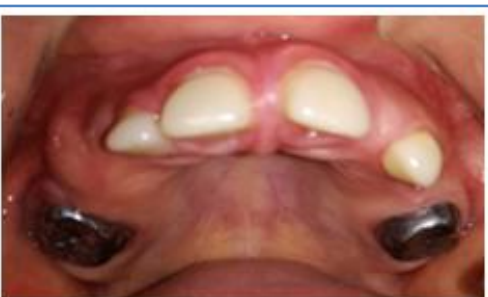

(a)

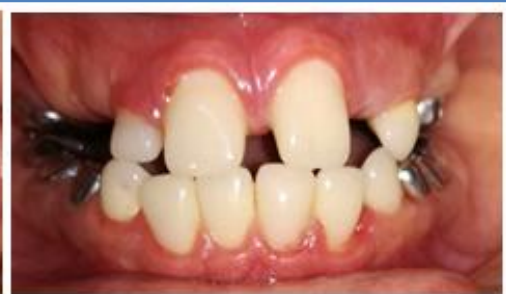

(b)

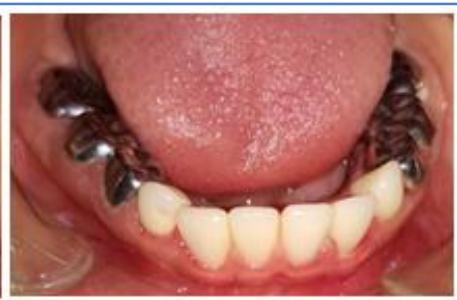

(c)

Fig-3: (a) maxillary occlusal view ; (b)Frontal view of the completed treatment with stainless steel crowns and composite resin-filled celluloid forms; (c) mandibular occlusal view.

Finally, a removable partial denture was indicated to replace teeth 53, 54, 55, 62, 64 and 65 (Fig. 4)

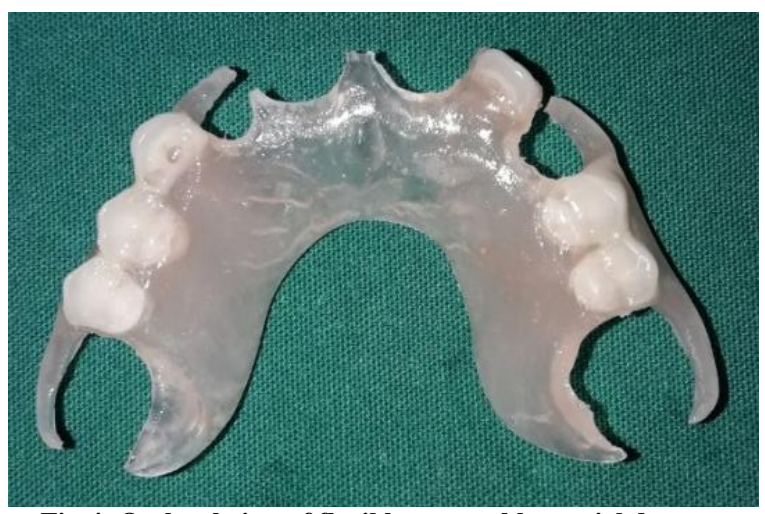

Fig-4: Occlusal view of flexible removable partial denture

Our aim was to treat the psycho-social as well as the functional and aesthetic problems. After the treatment, no negative situation was encountered during the follow up, and the patient reports being very satisfied.

\section{DISCUSSION}

AI is a developmental, often inherited disorder, affecting the primary and permanent dentition. It usually occurs in the absence of systemic features and comprises diverse phenotypic entities. The extensive rehabilitation of a young patient with a generalized AI is a challenge for the clinician, and a multidisciplinary team of professionals needs to be involved in the care plan [13].

Children with AI can have high dental needs and may present many dental challenges. Several factors have to be taken into consideration, including the age of the patient, the quality and quantity of existing enamel and tooth structure, the periodontal condition, and the long-term prognosis and stability of the result. The multiple treatment phases often last several years, and at each stage, the long-term consequences, risks, and benefits of the various therapy options must be discussed with patients and parents [14].The successful management of AI during childhood requires the cooperation and motivation of the patient and parents [15].
Treatment should begin as soon as possible according to patient compliance in office dental care. For very young patients, general anesthesia may be necessary. Stainless steel crowns were indicated in primary teeth with hypoplastic or hypomineralized AI in order to reduce tooth sensitivity and restore enamel loss. Composite resin restorations have been advocated to mask discoloration and improve dental esthetics. Composite resin restorations can be placed with minimal or no tooth preparation to preserve tooth structure and provided satisfactory esthetics. In the same context, the use of resin-filled celluloid forms in the maxillary and mandibular primary anterior teeth was the most suitable treatment for these patients. Composite restorations were indicated for all primary teeth.

In mixed dentition, rehabilitation must be done as soon as teeth erupt. Treatment main goals should be the preservation of tooth integrity and vitality [16]. Paediatric crowns can be easily performed on first molars without tooth preparation, especially indicated when teeth are painful or hypoplastic. Orthodontic elastic spacer was used to separate teeth. In other cases, only prophylactic care may be enough. In hypomineralized forms, glass ionomer cements on occlusal surfaces were efficient in preventing pain and allowing temporizing until teeth eruption was achieved.

In our patient, after considering her age, strip crown and composite resin were chosen for treating the anterior teeth to ensure her aesthetic requirements. Gingivectomy was applied at primary and first molars to obtain a healthy gum tissue around the teeth and to increase the retention of the restoration to these teeth. Temporary crowns or stainless steel crown can be used in patient with vertical dimension loss to ensure the occlusion [16]. In our case, a stainless steel crown was made to treat the decreased vertical dimension and to provide the function of the posterior teeth.

In the permanent dentition, the final treatment objectives are to diminish tooth sensitivity and to restore vertical dimension of occlusion, function, as well as esthetics. The final treatment often starts as soon as clinical height of the crown and the gingival tissue has been stabilized and the pulp tissues have receded. 


\section{CONCLUSION}

Amelogenesis imperfecta is a group of inherited disorders that pose diagnostic and restorative treatment challenges for dental care providers. There is currently no standard of care established for managing patient with AI although multidisciplinary approach may be advantageous. The cumulated evidence on outcomes of alternative restorations for each type of AI is critically needed [17]. With such evidence, clinicians may then select more favorable approaches to treat individual AI patient and to optimize their patient's oral health and longterm prognosis [18].

\section{ACKNOWLEDGEMENTS}

The author wish to thank the head of the pediatric department professor GHARBI Imen for her devotion and her availability

\section{REFERENCES}

1. Aldred, M. J., Savarirayan, R., \& Crawford, P. J. M. (2003). Amelogenesis imperfecta: a classification and catalogue for the $21 \mathrm{st}$ century. Oral diseases, 9(1), 19-23.

2. Urzúa, B., Martínez, C., Ortega-Pinto, A., Adorno, D., Morales-Bozo, I., Riadi, G., \& Reyes, M. (2015). Novel missense mutation of the FAM83H gene causes retention of amelogenin and a mild clinical phenotype of hypocalcified enamel. Archives of oral biology,60(9), 13561367.

3. Prasad, M. K., Geoffroy, V., Vicaire, S., Jost, B., Dumas, M., Le Gras, S., ... \& Leheup, B. (2016). A targeted next-generation sequencing assay for the molecular diagnosis of genetic disorders with orodental involvement. Journal of medical genetics, 53(2), 98-110.

4. Witkop Jr, C. J. (1988). Amelogenesis imperfecta, dentinogenesis imperfecta and dentin dysplasia revisited: problems in classification. Journal of Oral Pathology \& Medicine, 17(9-10), 547-553.

5. Gadhia, K., McDonald, S., Arkutu, N., \& Malik, K. (2012). Amelogenesis imperfecta: an introduction. British dental journal, 212(8), 377.

6. Smith, C. E., Poulter, J. A., Antanaviciute, A., Kirkham, J., Brookes, S. J., Inglehearn, C. F., \& Mighell, A. J. (2017). Amelogenesis imperfecta; genes, proteins, and pathways. Frontiers in physiology, 8, 435.

7. Souza, J. F. D., Fragelli, C. M. B., Paschoal, M. A. B., Campos, E. A., Cunha, L. F., Losso, E. M., \& Cordeiro, R. D. C. L. (2014). Noninvasive and multidisciplinary approach to the functional and esthetic rehabilitation of amelogenesis imperfecta: a pediatric case report. Case reports in dentistry, 2014.
8. Nusier, M., Yassin, O., Hart, T. C., Samimi, A., \& Wright, J. T. (2004). Phenotypic diversity and revision of the nomenclature for autosomal recessive amelogenesis imperfecta. Oral Surgery, Oral Medicine, Oral Pathology, Oral Radiology, and Endodontology, 97(2), 220-230.

9. Pavlič, A., Battelino, T., Trebušak Podkrajšek, K., \& Ovsenik, M. (2010). Craniofacial characteristics and genotypes of amelogenesis imperfecta patients. The European Journal of Orthodontics, 33(3), 325-331.

10. Toupenay, S., Fournier, B. P., Manière, M. C., IfiNaulin, C., Berdal, A., \& de La Dure-Molla, M. (2018). Amelogenesis imperfecta: therapeutic strategy from primary to permanent dentition across case reports. BMC oral health, 18(1), 108.

11. Oliveira, C. S., Kruschewsky, I., de Fátima Barbosa Fonseca, J., do Amaral, F. L. B., Arias Pecorari, V. G., Basting, R. T., \& Gomes França, F. M. (2011). Diagnosis and esthetic functional rehabilitation of a patient with amelogenesis imperfecta. Quintessence International, 42(6).

12. De Souza-e-Silva, C. M., Parisotto, T. M., SteinerOliveira, C., Gaviao, M. B. D., \& Nobre-DosSantos, M. (2010). Oral rehabilitation of primary dentition affected by amelogenesis imperfecta: a case report. Journal of Contemporary Dental Practice, 11(3), 71-77.

13. Gisler, V., Enkling, N., Zix, J., Kim, K., Kellerhoff, N. M., \& Mericske-Stern, R. E. G. I. N. A. (2010). A multidisciplinary approach to the functional and esthetic rehabilitation of amelogenesis imperfecta and open bite deformity: a case report. Journal of esthetic and restorative dentistry, 22(5), 282-293.

14. McDonald, S., Arkutu, N., Malik, K., Gadhia, K., \& McKaig, S. (2012). Managing the paediatric patient with amelogenesis imperfecta. British dental journal, 212(9), 425.

15. Lourenço Neto, N., Paschoal, M. A., Kobayashi, T. Y., Rios, D., \& Silva, S. (2010). Early oral rehabilitation of a child with amelogenesis imperfecta. J. Health Sci. Inst, 28(3), 246-248.

16. Cantekin, K., Simsek, H., \& Buyukbayrakdar, I. S. A Treatment Approach for a Young Patient with Severe Amelogenesis Imperfecta.

17. Lundgren, G. P., \& Dahllöf, G. (2014). Outcome of restorative treatment in young patients with amelogenesis imperfecta. a cross-sectional, retrospective study. Journal of dentistry, 42(11), 1382-1389.

18. Toupenay, S., Fournier, B. P., Manière, M. C., IfiNaulin, C., Berdal, A., \& de La Dure-Molla, M. (2018). Amelogenesis imperfecta: therapeutic strategy from primary to permanent dentition across case reports. BMC oral health, 18(1), 108. 